\title{
Artrópodes e a divulgação científica: uma oportunidade para o diálogo em saúde
}

\author{
Arthropods and science dissemination: an opportunity for dialogs in \\ health
}

\section{Thais Varandas de Azeredo ${ }^{1}$; Lucianne Fragel-Madeira ${ }^{2}$; Claudio Maurício Vieira de Souza $^{3}$; Grazielle Rodrigues Pereira ${ }^{4}$; Robson Coutinho-Silva ${ }^{5}$; Gustavo Henrique Varela Saturnino Alves ${ }^{6}$}

\begin{abstract}
1 Mestranda, Programa de Pós-graduação em Ciências e Biotecnologia,, Instituto de Biologia, Universidade Federal Fluminense, Niterói, RJ, Brasil e Especialista em Educação e Divulgação Científica - IFRJ, Mesquita, RJ, Brasil thaisvazeredo@gmail.com / https://orcid.org/0000-0002-6388-6537

2 Doutora, Professora do Departamento de Neurobiologia, Programa de Pós-Graduação em Ciências e Biotecnologia, Instituto de Biologia, Universidade Federal Fluminense, Niterói, RJ, Brasil - $\underline{\text { lfragel@id.uff.br / https://orcid.org/0000-0001- }}$ $\underline{6747-2828}$

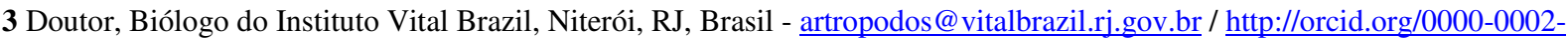
3978-5760

4 Doutora, Professora do Programa de Pós-Graduação em Ensino de Ciências, Instituto Federal de Educação, Ciência e Tecnologia do Rio de Janeiro, Nilópolis, RJ, Brasil; Professora do Mestrado Profissional em Educação, Gestão e Difusão em Biociências, Universidade Federal do Rio de Janeiro, Rio de Janeiro, RJ, Brasil - grazielle.pereira@ifrj.edu.br / https://orcid.org/0000-0001-5685-0205

5 Doutor, Professor do Programa de Pós-graduação em Ensino em Biociências e Saúde, Instituto Oswaldo Cruz, Fiocruz, e Professor Instituto de Biofísica Carlos Chagas Filho, Universidade Federal do Rio de Janeiro, Rio de Janeiro, RJ, Brasil rcsilva@ biof.ufrj.br / https://orcid.org/0000-0002-7318-0204

6 Doutorando, do Programa de Pós-graduação em Ensino em Biociências e Saúde, Instituto Oswaldo Cruz, Fiocruz, Rio de Janeiro, e Professor do Curso de Especialização Lato Sensu em Educação e Divulgação Científica, Instituto Federal de Educação, Ciência e Tecnologia do Rio de Janeiro, Mesquita, RJ, Brasil - gh_alves@id.uff.br / https://orcid.org/0000-00029100-1986
\end{abstract}

\section{Recebido em Dezembro/2019. Publicado em Abril/2020}

Palavras-chave: Popularização da ciência e da tecnologia. Centros e museus de ciência. Comunicação de saúde
RESUMO: Este trabalho apresenta a produção de escorpiões incrustados em resina e a experiência de sua utilização como material de divulgação científica no centro de ciências itinerante Ciências Sob Tendas. A partir desse material, buscou-se reconhecer as preferências do público sobre a atividade "Artrópodes", além de identificar suas potencialidades para a divulgação científica. Os dados foram coletados através da pesquisa participante, de filmagem em campo amplo e questionário misto, durante a visita à uma escola. Os resultados mostraram que os visitantes interagiram tocando no material, fotografando e dialogando entre si e com as mediadoras. A atividade não foi citada pelos visitantes como uma novidade, possivelmente por serem animais já conhecidos e presentes no cotidiano. Entretanto, os escorpiões se destacaram positivamente entre as atividades da exposição e as discussões entre eles e os mediadores abordaram temas diversos. Surgiram questionamentos sobre a periculosidade desses animais, como evitá-los e as formas de tratamentos em casos de acidentes. Assim consideramos a atividade "Artrópodes" como uma forma de divulgação científica que viabiliza a discussão de diversos temas, inclusive de saúde.

ABSTRACT: This paper presents resin-inlaid scorpions' production and their use as a scientific dissemination material at the science center Ciências Sob Tendas. From this material, we intent to recognize the public's perception about the "Arthropod"
Science and technology popularization. Science 
centers and museums. Health communication. activity, and identify its potential for scientific dissemination. Data were collected through participant survey, wide field filming and questionnaire during a visit to a school. The results shown that visitors interacted by touching the material, photographing and dialoguing with each other and with mediators. The activity was not mentioned by visitors as a unique, possibly because these animals are already known by then and present in their daily life. However, the scorpions stand out positively among others activities in the exhibition and the discussions between them and the mediators addressed a diverse of topics. Questions were raised about the dangerousness of these animals, how to avoid them and how to proceed in case of accidents. Thus, we consider the "Arthropods" activity as a form of scientific dissemination that enables discussions about several topics, including health.

\section{INTRODUÇÃO}

Os artrópodes formam o maior filo do reino animal, ocupam uma grande variedade de nichos ecológicos e diversos ecossistemas. Suas adaptações evolutivas permitiram que dominassem ambientes marinhos, terrestres, micro e macroscópicos (AQUINO; AGUIARMENEZES; DE QUEIROZ, 2006).

A convivência desses animais com os seres humanos pode, em alguns casos, trazer riscos à saúde, pois estes atuam como vetores biológicos de diversas doenças. O mosquito (Diptera: Culicidae) Aedes aegypti, por exemplo é encontrado em ambientes antrópicos de regiões tropicais e está relacionado com a transmissão da Dengue, Febre Amarela, Febre Chicungunha e Zika. Este último causou, no Brasil, uma emergência nacional em saúde, pois está relacionado com o nascimento de crianças com microcefalia. (CASTILHOS; ALMEIDA, 2018).

Outro grupo de artrópodes que põe em risco a saúde humana são os aracnídeos. A classe Arachinida é representada por animais como escorpiões (Scorpiones), opiliões (Opiliones), ácaros (Acari) e aranhas (Araneae). As aranhas e escorpiões são caracterizados como animais peçonhentos, ou seja, aqueles animais que possuem glândulas de veneno e podem injetá-los em suas presas ou potenciais ameaças (BERTANI; GODÉ, 2015). Algumas espécies apresentam riscos para a vida dos seres humanos pois a ação das toxinas está diretamente relacionada ao sistema nervoso. A forte relação desse grupo com os humanos é refletida na sua presença na cultura popular como na astrologia e mitologias; literatura; filmes de ficção e inspiração para heróis de histórias em quadrinhos (DA-SILVA et al., 2014).

Para além disso, essa relação também é fundamentada no interesse médico. No Brasil, foram notificados em 2016 mais de 162 mil casos de acidentes por animais peçonhentos - serpentes, aranhas, escorpiões, lagartas e abelhas - e os aracnídeos foram responsáveis por quase $75 \%$ destes acidentes.

Acredita-se que a frequência dos acidentes com aranhas e escorpiões está aumentando pois, muitos desses animais estão se tornando comuns em meios urbanos (SOUZA; MACHADO, 2017). O crescimento urbano desordenado, a falta de saneamento 
básico, a coleta irregular de lixo, as construções precárias em alvenaria, o desmatamento, e consequente desequilíbrio ecológico fazem com que esses aracnídeos busquem abrigo e alimento cada vez mais próximos aos seres humanos e de suas rotinas (CHEUNG; MACHADO, 2017). Essas mudanças no hábitat favorecem a predominância de grupos mais adaptáveis sobre aqueles mais sensíveis o que altera diversas relações ecológicas. Além disso, as casas favorecem a criação de novos esconderijos contra predadores naturais como ralos de banheiros, caixas de papelão, telhados e armários. Além de disponibilizar maior oferta de alimento como mosquitos, baratas e outros insetos associados ao acúmulo de lixo (BIAZI, 2015).

A presença desses animais peçonhentos tão perto dos seres humanos está alterando o perfil epidemiológico dos acidentes ao longo dos anos (RECKZIEGEL, 2014). Para esses acidentes há tratamento que consiste em duas abordagens: a específica e a sintomática, cabendo à equipe médica julgar cada caso e tomar as medidas necessárias. $\mathrm{O}$ tratamento específico é a soroterapia e tem como objetivo neutralizar o veneno circulante através de anticorpos específicos para cada tipo de toxina. O tratamento sintomático consiste em amenizar as consequências do veneno no organismo podendo ser utilizados analgésicos para alívio da dor, compressas frias, antibióticos, controle dos sinais vitais, antisséptico local e limpeza periódica da ferida. (BRASIL, 2001; INSTITUTO BUTANTAN, 2018).

Portanto, informar a população sobre o risco de acidentes com aranhas e escorpiões, profilaxias e o tratamento é importante visto que, quanto mais rápido o soro for administrado, menores serão os riscos de sequelas ou óbito. Busato e colaboradores (2015) analisaram a percepção de estudantes sobre animais peçonhentos e constataram que a maioria indica corretamente os grupos de importância médica - aranhas, escorpiões, serpentes e lagartas. Porém em relação ao tratamento, diversos relatos são voltados para o conhecimento popular, tais como: lavar a ferida com água e sal, fazer torniquete, sugar o veneno etc. Essa falta de informações sobre primeiros socorros e tratamentos contribuem para o aumento do número de casos com sequelas (FERREIRA; SOARES, 2008). Contudo, estes estudantes, em sua maioria, mencionaram a necessidade de ir ao hospital após o acidente, o que está de acordo com o Manual produzido pela Fundação Nacional de Saúde (FUNASA) (BRASIL, 2001) para diagnóstico e tratamento desses acidentes.

Com o objetivo de atingir um público amplo com informações científicas e tecnológicas, a divulgação científica (DC) propõe ações com os mais diversos recursos, técnicas e produtos para que haja essa veiculação de informações (BUENO, 2010). Podem ser considerados formas para esta prática: museus, exposições, feiras de ciências, revistas, jornais, noticiários televisivos, materiais paradidáticos e centros de ciências (NASCIMENTO; 
REZENDE, 2016; ROCHA; MARANDINO, 2017). Apesar de tantos caminhos para a DC, o público é o fator de maior relevância. Sendo assim, identificar para quem e com quais intenções as ações serão desenvolvidas permite a reformulação discursiva para uma linguagem acessível (BUENO, 2010), bem como pensar a forma de interação do público com tais ações pode nortear o meio pelo quais serão desenvolvidas (WAGENSBERG, 2000).

A DC se diferencia nela mesma, em tendências de conceitos e práticas. A popularização da ciência é uma dessas tendências, e está diretamente relacionada com a participação popular, com a reflexão e a vida cotidiana. Sua participação no processo educativo busca a apropriação do conhecimento científico através de atividades que fomentem a curiosidade, o pensamento crítico e a consciência cidadã, permitindo que o indivíduo atente para questões sociais, ambientais e econômicas (GERMANO; KULESZA, 2007; ALVES, 2016).

Nesse processo, os museus e centros de ciências são exemplos de espaços que proporcionam para o público geral - não só estudantes - acesso a conhecimentos sem um sistema progressivo de conteúdo, com um tempo de aprendizagem flexível e valorização da troca de experiências, além de objetivos educacionais bem definidos (CASCAIS; TERÁN, 2014; GADOTTI, 2005).

Não se deve negar, entretanto, que a distribuição desses locais pelo território brasileiro é extremamente desigual. Ainda mais grave que as diferenças regionais, estão aquelas existentes dentro do próprio estado, já que as capitais e regiões metropolitanas costumam ter maior concentração desses espaços que os subúrbios e zonas rurais. O estado do Rio de Janeiro possui 45 museus e centros de ciência, dos quais 28 estão situados na capital (ABCMC, 2015; ROCHA; MARANDINO, 2017).

Para cumprir seu papel transformador e alcançar regiões de vulnerabilidade social, alguns museus e centros de ciência fortaleceram nos últimos anos as atividades itinerantes aquelas que expõem ou transportam seu material em veículos como carretas, ônibus e vans (ROCHA; MARANDINO, 2017). Dessa forma, é possível levar para populações que tem pouco ou nenhum acesso a atividades culturais e científicas ações que promovam a sensibilização e compreensão da ciência e da tecnologia, para além de conceitos científicos.

Nessa perspectiva, o Ciências Sob Tendas (CST), centro de ciências itinerante situado em Niterói, leva atividades por todo estado do Rio de Janeiro, abordando diversos temas em ciência e tecnologia, inclusive sobre saúde (ALVES, 2016). Uma de suas atividades é a coleção de artrópodes incrustados em resina, composta por diversos representantes das classes dos insetos, aracnídeos, diplópodes e quilópodes. A partir dela os mediadores da atividade podem dialogar com o público visitante sobre a diversidade ecológica do grupo, a 
influência deles sobre a saúde humana, e especialmente, sobre a prevenção de acidentes com escorpiões e seu tratamento. Os temas relacionados a esses aracnídeos são enfatizados na mediação devido ao grande número de casos que ocorre anualmente nos municípios do Rio de Janeiro.

Assim este trabalho se apresenta numa perspectiva de avaliação em centros e museus de ciências, e para tal consideramos a concepção de Cury (2005) na qual:

“a avaliação em museus não poderia ter como fim único provar ou jugar (se é bom ou mau) programas ou processos, mas, principalmente, criar um sistema de informações sobre aspecto da realidade que - quando munidos de significado possam intervir positivamente sobre essa realidade. (Cury, 2005, p. 125)"

Ou seja, os museus devem fazer avaliações sistemáticas periodicamente buscando o aperfeiçoamento e a compreensão do trabalho que é desenvolvido. O estudo de visitantes é uma das categorias avaliadoras. Portanto, espera-se reconhecer as preferências do público em relação aos materiais e as abordagens da atividade Artrópodes, além de identificar suas potencialidades para a divulgação científica, caracterizando o estudo como uma avaliação somativa.

Por conseguinte, visou-se avaliar a utilização de artrópodes, em especial os escorpiões, como material de divulgação científica durante as exposições do Ciências Sob Tendas. Através de observação participante, questionário e filmagem observou-se que, apesar dos animais da classe Arthropoda serem conhecidos pela maioria do público, a atividade em questão foi bem recebida pelos visitantes. Os visitantes discutiram com as mediadoras sobre saúde, diferenças entre os grupos de animais e curiosidades, além de interagirem com o material nas mãos. Por fim, a atividade destacou-se positivamente, sendo a segunda mais preferida entre as demais apresentadas na exposição. Assim, consideramos que a atividade dos Artrópodes no CST é uma forma de divulgação científica que viabiliza a discussão de diversos temas, em especial temas de saúde.

\section{METODOLOGIA}

A pesquisa foi desenvolvida no centro de ciências itinerante Ciência Sob Tendas (CST). Este centro de ciência é um programa de extensão da Universidade Federal Fluminense e sua missão é ampliar a oferta de atividades científicas de caráter lúdico, interativo e criativo para o público visitante, propiciando a sensibilização e compreensão pública da ciência e da tecnologia. Acreditando, portanto, estar contribuindo para a difusão e popularização de conhecimentos científicos (ALVES, 2016).

Por ser itinerante, as atividades do CST ocorrem em diversos locais, porém, limitando-se ainda ao Estado do Rio de Janeiro e sua movimentação e armazenamento do acervo é realizada por um reboque baú com, aproximadamente, 6,5 metros cúbicos. 
Todas as atividades do CST são elaboradas, estruturadas, organizadas e mediadas por membros da equipe, bolsistas ou não, e devem respeitar os seguintes fatores: baixo custo, resistência à manipulação contínua, tamanho reduzido e que a duração estimada da interação seja breve, em média cinco minutos. Essa preocupação com o tempo de interação se faz necessária uma vez que, muitos grupos escolares que visitam o CST dispõem de, em média, uma hora para interagir com toda a exposição.

As visitas do CST têm duração de um dia e podem ocorrer em praças, praias, parques e escolas. Nos dias de exposição, antes da abertura para o público, a equipe se organiza em ações específicas para viabilizar a exposição: realizar a montagem das tendas e mesas, dividir a equipe de mediadores por atividades e realizar o treinamento, fazer a montagem das atividades e preparar o sistema de avaliação da exposição. No treinamento geral são abordados temas como os objetivos a serem alcançados ao longo da exposição, a postura esperada de um mediador e, principalmente, a diferença entre mediar e ministrar uma aula. $\mathrm{O}$ treinamento específico das atividades é realizado pelo membro da equipe responsável por ela e mais experiente nos temas e discussões que são suscitadas. Ele deve nivelar os conhecimentos do novo mediador acerca do assunto e expor as principais questões envolvidas em cada atividade. Após iniciado, o atendimento ao público perdura até às 17 horas (ALVES, 2016).

\section{Desenvolvimento dos produtos da atividade Artrópodes}

Para a confecção do produto foram utilizados mudas e carcaças de escorpiões da coleção científica do aracnário do Instituto Vital Brazil (IVB). Este instituto é uma referência em estudos e pesquisas nos campos de diagnósticos laboratoriais e epidemiológicos e em programas de controle de doenças que ameacem a saúde pública do Estado do Rio de Janeiro. Ativo desde 1919 o IVB, com sede e filial no estado do Rio de Janeiro, produz e distribui soros de diversos animais peçonhentos por todos os estados brasileiros (INSTITUTO VITAL BRAZIL, 2018).

O aracnário do IVB é responsável pela criação de escorpiões da espécie T. serrulatus para extração de veneno a partir do qual será produzido o soro. Além disso, exemplares de diversas espécies são doados ao aracnário para compor sua coleção científica. Em virtude da disponibilidade de material no IVB as espécies $T$. serrulatus e $T$. costatus foram escolhidas para compor a coleção de artrópodes do CST.

O Tityus serrulatus, também conhecido como escorpião amarelo apresenta uma grande capacidade adaptativa e é a espécie responsável pela maioria dos acidentes graves no Brasil. O veneno desta espécie possui ação sobre o sistema nervoso autônomo, causando efeitos como náuseas, vômitos, sudorese, arritmias cardíacas, danos ao miocárdio e edema 
pulmonar, apresentando mortalidade de aproximadamente $1 \%$ dos casos. Sua distribuição abrange quase todas as regiões brasileiras, com exceção do Norte do país e sua reprodução é partenogenética, sendo assim a espécie é composta somente por fêmeas, com grande capacidade adaptativa (NENCIONI et al., 2018; RECKZIEGEL, 2014).

O Tityus costatus é uma espécie muito semelhante a anterior, principalmente se analisada por não especialistas, sua coloração apresenta tons amarelos e marrons na maior parte do corpo e pedipalpos com manchas vermelhas e pinças bem escuras, diferentemente da anterior, esta espécie tem reprodução sexuada e comportamento de corte com sequências complexas de ritos. Sua distribuição abrange o bioma Mata Atlântica das regiões Sul e Sudeste. Pouco se sabe sobre a toxicidade de seu veneno e até mesmo sobre o índice de acidentes, pois muitos deles podem ser associados por engano ao T. serrulatus e T. bahiensis (LOURENÇO, 2015; RECKZIEGEL, 2014).

Para a produção dos blocos de resina utilizamos metodologias semelhantes à Arte em Resina (2018) e Kiem e Ribas (2015). Os exemplares utilizados foram colocados para secar diretamente ao sol por 5 horas durante 5 dias, objetivando a retirada de líquidos e a preservação da posição desejada (Figura 1).

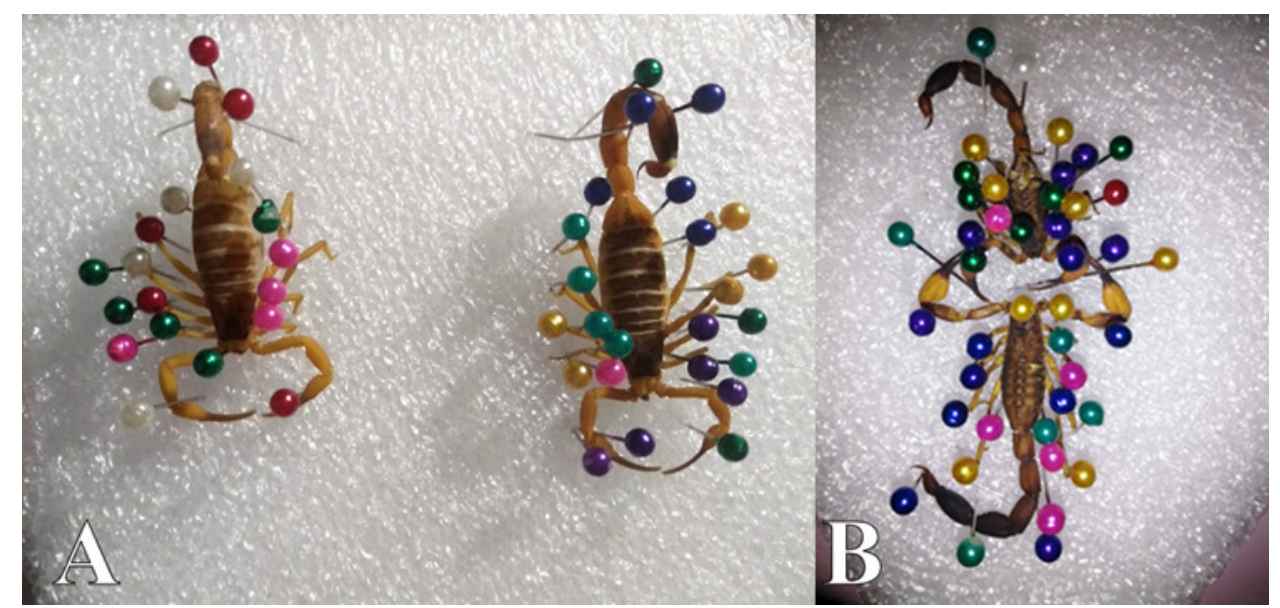

Figura 1- Carcaças de escorpiões retiradas do álcool e colocadas na posição de interesse com auxílio de alfinetes para posterior secagem ao sol. Em A T. serrulatus e em B T. costatus.

Fonte: Elaborado pelos autores.

Para incrustação utilizamos resina poliéster cristal e seu catalisador. O manuseio da resina requer itens de segurança como luvas de látex, jaleco e um local arejado, é válido ressaltar que a inalação da resina pode causar tonturas e irritação no nariz e olhos. As formas utilizadas foram de dois materiais: silicone e Tetra Pak, esta última confeccionada artesanalmente. A aplicação da resina foi feita em camadas (Figura 2). Entre cada camada esperamos a cura de uma hora e, após a última camada, esperamos 10 dias para desenformar completamente o produto e seguir para a etapa de acabamento. 


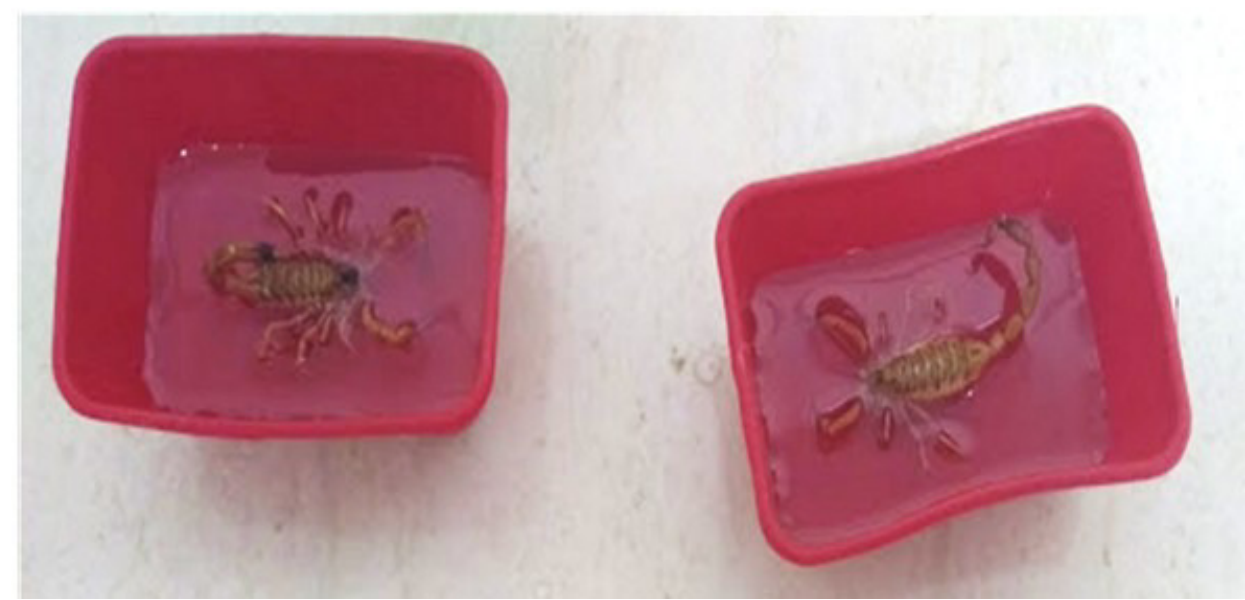

Figura 2 - Forma de silicone com as duas primeiras camadas de resina envolvendo $T$. Serrulatus.

Fonte: Elaborado pelos autores.

O acabamento consiste em dois processos: lixar com lixas d'água de diversas gramaturas e polir com massa de polir e panos de microfibra. Vale lembrar que depois de pronto, os blocos de resina não apresentam risco à saúde do público, mas caso quebrem podem se partir em peças pequenas podendo ser engolidas.

Outro produto produzido para a atividade de aracnídeos peçonhentos foi uma caixa escura com lâmpada de luz ultravioleta (UV) onde foram utilizados carcaças e mudas de escorpiões $T$. serrulatus para visualização da fluorescência ciano-esverdeada, característica da maioria das espécies de escorpiões, quando em exposição à essa luz (Figura 3). A caixa escura foi confeccionada utilizando uma caixa de MDF de artesanato com tampa. Na tampa, cortamos uma abertura para servir de visor para o interior da caixa. Na lateral da caixa foi feita uma abertura para o bocal da lâmpada de luz UV e dele parte um fio com interruptor que permite ligar e desligar a lâmpada - sendo necessária uma fonte de energia $127 \mathrm{v}$.

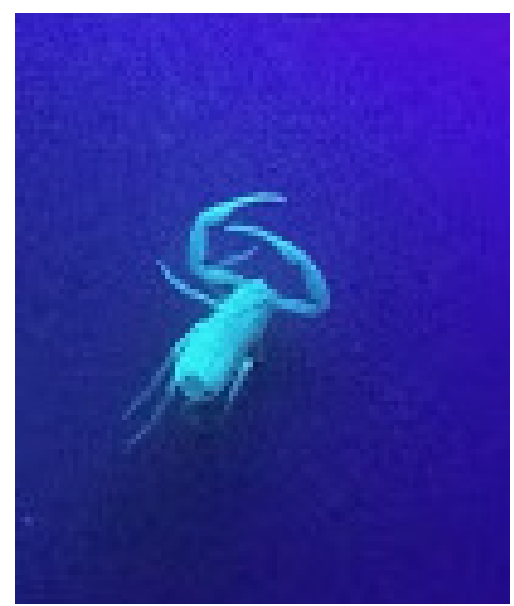

Figura 3 - Muda de escorpião dentro da caixa escura e sob a incidência da luz negra. Fonte: Elaborado pelos autores.

\section{Características do público analisado}


Os dados referentes a essa pesquisa foram fruto da exposição do CST realizada no mês de julho de 2018 ao CIEP 172 Nelson Rodrigues em Nova Iguaçu, RJ. Neste município foram notificadas 31 ocorrências de acidentes com animais peçonhentos em 2016, sendo, os escorpiões responsáveis por 2 desses casos, enquanto as serpentes lideram o quadro com 13 acidentes notificados (BRASIL, 2016). Importa ainda destacar que é nesse município que se encontra o Hospital Geral de Nova Iguaçu, polo de atendimento para pessoas que tiveram acidentes com animais peçonhentos e recebe do Ministério da Saúde os soros de várias espécies (INSTITUTO VITAL BRAZIL, 2018). A escola possui cerca de 800 alunos com turmas do Ensino Fundamental II, Ensino Médio e Educação de Jovens e Adultos (EJA).

Neste dia foram atendidas pelo CST mais de 200 pessoas. O público que respondeu ao questionário tinha idades entre 10 e 21 anos, majoritariamente adolescentes com escolaridade variando dos anos finais do Ensino Fundamental (cursando) até o Ensino Médio (completo). Houve predominância de visitantes do sexo feminino. Esses dados correspondem ao esperado para uma exposição realizada em escola (BRASIL, 2009).

\section{Instrumentos de coleta de dados}

Os dados para avaliação da atividade Artrópodes foram coletados através de pesquisa participante, questionário aberto e filmagem em campo amplo, caracterizando a pesquisa como qualitativa.

\section{Pesquisa participante}

A pesquisa participante foi baseada em Angrosino (2000) e Marques (2016). Nestes trabalhos os autores discutem a manutenção da objetividade quando o pesquisador é um membro ativo da pesquisa já que essa metodologia permite a interação entre pesquisador e os sujeitos. Apesar dessas questões, eles apontam que, para as pesquisas em educação, a realidade pode ser estudada mais profundamente e assim, apontadas as questões mais relevantes para cada grupo.

Portanto, nessa etapa da pesquisa buscou-se conhecer quais eram os questionamentos e discussões do público quando participava da atividade. Para tal uma das autoras do trabalho, atuou como mediadora na atividade juntamente com duas voluntárias do CST. Este fato a permitiu estar próxima do público para captar tais informações.

Durante a mediação buscou-se abordar a classificação taxonômica e as diferenças morfológicas entre os grupos; a presença dos animais no cotidiano do visitante; curiosidades sobre alimentação e reprodução; a possibilidade de serem nocivos a nossa saúde, e a periculosidade e métodos de prevenção de acidentes com escorpiões. Os dados coletados sobre as discussões durante a mediação foram anotados em caderno de campo para posterior avaliação. 


\section{Questionário}

O questionário com perguntas abertas foi aplicado por meio do sistema de avaliação do CST. Essa avaliação buscou investigar a opinião do público sobre a exposição como um todo, mas possuía perguntas específicas para a análise da atividade dos artrópodes. Para obtenção das respostas é designado um grupo de mediadores que são responsáveis por fazer a coleta de dados, sendo vedada a participação de qualquer um dos pesquisadores envolvidos neste trabalho.

Para participar da avaliação, o visitante deveria ter passado por, pelo menos, seis atividades da exposição do CST. O controle dessa frequência foi realizado através de um cartão que foi furado a cada atividade visitada. O questionário estava disponível pelo Googleforms em um tablet que foi utilizado para coleta de respostas. Outro tablet estava conectado a uma impressora e realizava o registro fotográfico e impressão com uma moldura do CST. Essa gratificação é considerada importante pelo CST, pois gera uma motivação extrínseca no público em realizar a avaliação (ALVES, 2016).

As perguntas do questionário buscavam caracterizar o público quanto a idade, sexo, escolaridade. Além disso, continha perguntas sobre a exposição e as atividades. Para essa pesquisa foram analisadas as respostas às seguintes perguntas: "O que você viu no CST que nunca havia visto antes?"; "Entre as coisas que você viu hoje no CST qual você gostou mais?" e "Na atividade dos artrópodes o que você mais gostou?".

Filmagem de campo amplo

A filmagem é uma metodologia que possibilita que um evento seja analisado pelo pesquisador diversas vezes. Através dessas avaliações o pesquisador pode formar novos questionamentos, grupos temáticos e caminhos de observação relevantes para sua pesquisa. Vale ressaltar que a câmera não interfere no comportamento dos participantes durante todo o processo de avaliação, podendo causar estranhamento apenas nos primeiros minutos (BELEI et al., 2008).

Portanto, para a filmagem, foi colocada uma câmera em um suporte alto com distância de 3 metros das mediadoras à exemplo da Figura 4. No início da exposição foi colocado um aviso genérico de que a exposição, como um todo, poderia ser filmada.

A partir desta metodologia esperava-se identificar as formas de interatividade entre visitante e os objetos da exposição baseada em Wagensberg (2000) tais como hands-on, minds-on, hearts-on; e o explainers-on proposta por Pavão e Leitão (2007). O tempo de permanência de cada atividade também foi quantificado. A contagem do tempo de cada participante foi marcada, no início, pelo diálogo com o mediador ou a interação com as peças e terminava quando o visitante se afastava da mesa. Como critério de análise se fez necessário 
ver o rosto do visitante na imagem para iniciar a contagem. Dessa forma, a chegada de visitantes, tanto em grupos quanto sozinhos, possibilitou o registro de eventos distintos e individuais. Também foram contabilizados como eventos os casos de retornos às atividades desde que houvesse nova interação (ALVES, 2016).

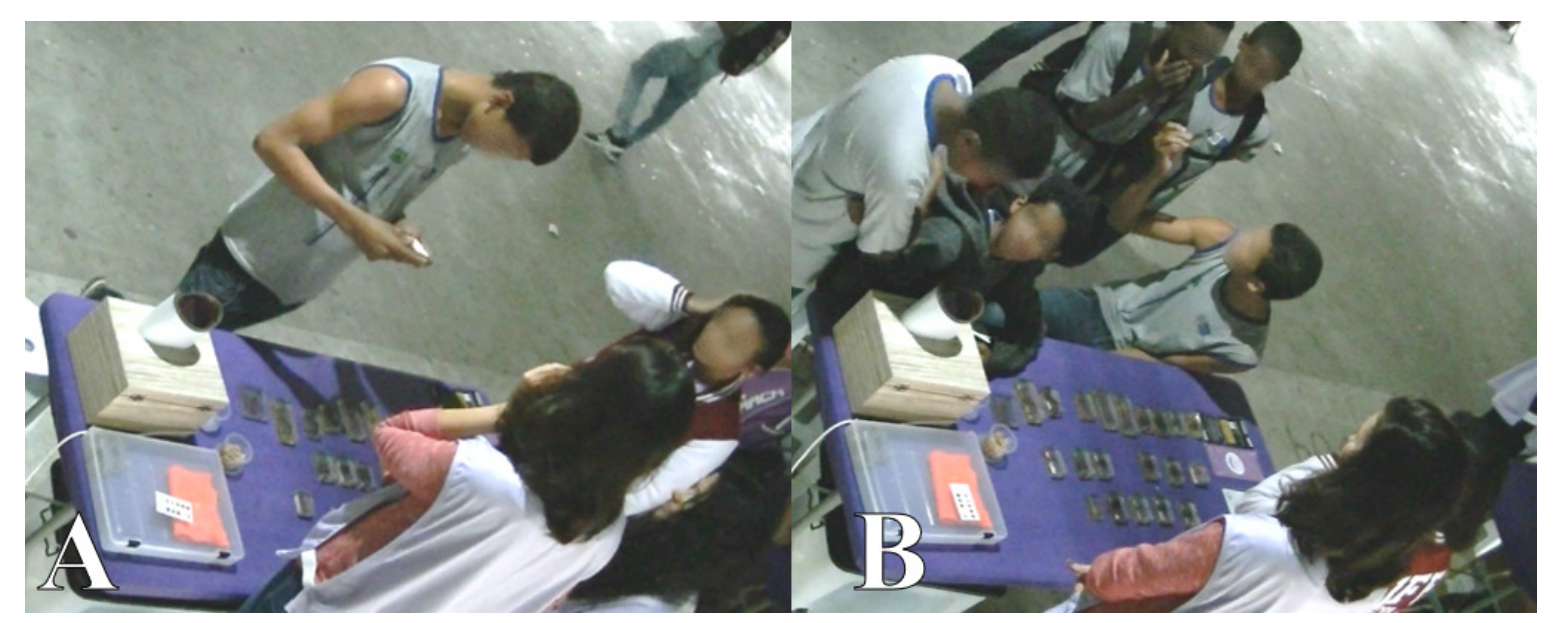

Figura 4 - Imagem da câmera usada para avaliar as interações. Em A o estudante está sozinho enquanto em B está mostrando a atividade a outros alunos.

Fonte: Elaborado pelos autores.

Análise dos dados

Os dados tanto da pesquisa participante quanto da filmagem foram avaliados pela metodologia proposta por Fontoura (2011). Através dessa metodologia foi possível elaborar esquemas de interpretação dos resultados a partir dos dados que se revelaram durante a observação dos vídeos e da leitura do caderno de campo. A análise dos relatos no caderno de campo fora reunida nos seguintes núcleos temáticos: (1) diálogos sobre saúde; (2) relatos de emoções negativas tais como medo ou nojo. Já para a filmagem, os dados foram agrupados baseando-se nas atitudes dos visitantes: (1) tempo de permanência e o retorno a atividade sozinhos ou acompanhados, (2) a interação com os objetos - fazer fotografia do material e pegar as carcaças de escorpião na mão e (3) interação com as mediadoras.

Em relação ao questionário, após finalizado, o programa converteu os dados para uma tabela em EXCEL podendo ser agrupados e quantificados. Os dados apresentam os números absolutos das respostas e seus percentuais. Esses dados foram discutidos segundo as questões propostas por Alves (2016) para a realidade do CST.

\section{RESULTADOS E DISCUSSÃO}

\section{Produtos desenvolvidos}

A incrustação em resina é um método que permite conservar espécimes biológicos em blocos translúcidos para fins didáticos, tem alta resistência ao manuseio, é durável e sua 
confecção pode ser considerada de baixo custo observando-se a longevidade que o produto tem em relação a outros (KIEM; RIBAS, 2015).

Ao todo foram produzidos três blocos de resina com escorpiões incrustados. Esse produto está incorporado ao acervo do CST e apresentou bom rendimento, resistência e funcionalidade dentro da atividade dos artrópodes. A incrustação em resina é um material que pode ser utilizado em escolas para aulas práticas de ciências (KIEM; RIBAS, 2015), bem como em atividades itinerantes de promoção da saúde (SUAREZ-FONTES et al., 2018).

No que diz respeito a caixa escura, optamos por abrir espaço apenas para um visor na tampa, uma vez que, geralmente, as atividades do Ciências Sob Tendas são ao ar livre e a luz do sol atrapalharia a visualização da característica desejada que é a fluorescência dos escorpiões. As dobradiças entre a tampa e a caixa facilitaram e permitiram que o visitante visse seu interior e manuseasse os objetos e carcaças ali dispostos. Além disso, devido as mudas e carcaças serem muito leves e estarem expostas em local aberto, por vezes elas voaram, o que ocasionou na perda ou danificação desse material, sendo um ponto desfavorável na exposição.

A fluorescência é uma característica que ainda não tem uma função conhecida entre especialistas da área. Brites (2018) reúne em seu trabalho algumas possibilidades para a presença da fluorescência, tais como: forma de localizar abrigo, comunicação intraespecífica durante o acasalamento, atração de presas, uma forma de bloquear raios solares ou até subprodutos metabólicos, não tendo função específica. Independentemente de sua função, Brites (2018) enfatiza que diversos pesquisadores propuseram que sua fluorescência fosse utilizada como ferramenta para coleta de espécimes em campo.

\section{Avaliação dos produtos na exposição do CST}

Pesquisa participante

Na condição de mediadora da atividade foi possível acompanhar a construção dos diálogos sobre os artrópodes. Em geral, no primeiro contato, o público buscava identificar quais animais estavam nos blocos de resina, o que também foi visto em pesquisa realizada por Busato e colaboradores (2015) onde a maioria dos estudantes indicou corretamente os animais de importância médica. A partir daí, as mediadoras conduziram a mediação fazendo perguntas sobre as diferenças morfológicas entre os grupos, trazendo curiosidades sobre alimentação e reprodução e saúde, fornecendo dicas para que o próprio visitante respondesse suas dúvidas. Para Marandino e colaboradores (2008), incentivar a participação do visitante estimula o aprendizado, a observação e promove o exercício da cidadania. Em seu trabalho, os autores discutem a educação em museus com foco na mediação e formação dos mediadores e enfatizam que, ao final da visita, não se espera dos visitantes quantidade de conteúdo 
aprendido, mas qualidade nos novos significados que foram estabelecidos através das relações humanas.

Dentre os assuntos frequentes trazidos pelos visitantes estavam aqueles relacionados com a periculosidade desses animais e a potência do veneno. A partir dessa demanda se iniciava, por exemplo, uma conversa sobre os ambientes favoráveis para o aparecimento dessas espécies, como evitá-los e as formas de tratamentos em casos de acidentes. Em alguns momentos um visitante trazia para discussão o caso de um conhecido que havia se acidentado. A reincidência desse assunto aponta para a frequência e para o perfil epidemiológico desses acidentes (RECKZIEGEL, 2014). Assim, reforça-se a necessidade de abordar assuntos científicos com um público amplo por meio da divulgação científica, seja ela por revistas, jornais, noticiários ou museus e centros de ciências (BUENO, 2010).

Quando as mediadoras ofereciam aos visitantes para segurar a carcaça de escorpiões fora da resina, muitos se mostraram relutantes, mas alguns aceitaram depois de ver os outros fazendo. Houve o caso de um aluno que quis colocar luva para pegá-los, pois assim participaria da atividade, mas não precisaria tocar neles. Em outro momento uma menina reagiu com um grito quando viu o animal na mão de seu colega. Esse tipo de reação pode ser compreendida ao observar a reputação ruim que alguns animais recebem: animais nocivos, sujos, transmissores de doenças e vistos como pragas (MIRANDA; FIGUEIREDO, 2009).

Wagensberg (2000) descreve e classifica as formas de interação do visitante com atividades em museus de ciências e a influência que possuem nas experiências vividas. $\mathrm{O}$ hands-on, ou seja, a interação manual estaria presente na possibilidade de tocar nos blocos de resina, segurar as carcaças de escorpião na mão e analisá-los livremente. Além disso, a familiaridade com o tema, as discussões com o mediador e os outros visitantes sobre saúde e experiências pessoais relacionam-se com o minds-on, que é a interação intelectual essencial em atividades como estas, proporcionando reflexões individuais e/ ou coletivas. As emoções experienciadas durante a visita, sejam elas positivas ou negativas (surpresa, medo, nojo, etc) influenciam também na forma como o indivíduo se relaciona com a atividade e assim constituem a interação hearts-on (WAGENSBERG, 2000). Complementarmente, a interação entre público e mediador adiciona-se aos outros tipos de interação e se enquadra na proposta de Pavão e Leitão (2007) onde a interação entre o público e a equipe educativa dos museus que são por muitas vezes chamadas de mediadores, o explainers-on.

Complementarmente, Carvalho e Lopes (2016), em estudo com crianças em museus, observaram que as diversas sensações despertadas diante das novidades e descobertas são condições que favorecem a imaginação, a construção do conhecimento e o sentimento de 
admiração pelas coisas do mundo. Por este motivo, as propostas educativas devem respeitar o ritmo das crianças de se encantar diante das peças que as interessarem.

Apesar da boa receptividade do público ao material fora da resina é importante refletir sobre essa possibilidade de tocar nos animais e as concepções controversas que isso pode trazer. Por exemplo, caso uma pessoa passe pela atividade sem ter participado da mediação, ela irá entender que segurar o animal vivo é algo seguro? Ou ainda, se o público for crianças da educação infantil, conseguirão eles distinguir as situações mesmo com a fala do mediador? Esses questionamentos são importantes pois geram informações que permitem a (re) orientação adequada de atividades novas e existentes no museu (CURY, 2005).

Questionário

Ao todo, 40 visitantes responderam ao questionário do sistema de avaliação. A primeira pergunta sobre as atividades era aberta e buscava conhecer "O que você viu no CST que nunca havia visto antes?". Dentre as 10 atividades expostas no dia, a atividade Artrópodes apresentou a menor porcentagem (Quadro 1). Este dado é compreensível visto que esses animais estão presentes nas casas e no dia a dia dos visitantes - por exemplo lacraias, baratas e besouros - devido a sua diversidade e abundância, ao crescimento urbano desordenado e a falta de saneamento básico. Esses fatores fazem alguns artrópodes de importância médica busquem abrigo e alimento cada vez mais próximos aos seres humanos e de suas rotinas (BESERRA; BRITO, 2008; CHEUNG; MACHADO, 2017). Em contrapartida, as peças anatômicas plastinadas mostram partes do corpo humano e de outros vertebrados que não poderiam ser visualizadas, muito menos tocadas em outras situações, foram a mais citada com 33,3\%. A opção "outros" inclui respostas indefinidas, tais como: tudo, nada ou não sei.

Quadro 1 - Respostas para a pergunta "O que você viu no CST que nunca havia visto antes".

\begin{tabular}{|c|c|}
\hline O que você viu no CST que nunca havia visto antes? \\
\hline Atividade & Porcentagem \\
\hline Peças anatômicas & $33,3 \%$ \\
\hline Papel que brota & $16,7 \%$ \\
\hline Células & $11,9 \%$ \\
\hline Outros & $11,9 \%$ \\
\hline Eletrocondutividade & $9,5 \%$ \\
\hline Libras & $7,1 \%$ \\
\hline Microscópios & $4,8 \%$ \\
\hline Artrópodes & $4,8 \%$ \\
\hline Total & $\mathbf{1 0 0 \%}$ \\
\hline
\end{tabular}

Fonte: Elaborado pelos autores.

No que diz respeito a pergunta "Entre as coisas que você viu hoje no CST, qual você gostou mais?” os artrópodes se destacam na segunda posição, atrás apenas das peças 
anatômicas (Quadro 2). Apesar de não ter se apresentado anteriormente como uma atividade inédita, esse destaque para os Artrópodes pode estar associado às formas de interação do visitante com os objetos. Como já mencionado, esta atividade trabalhou todas as formas de interatividade propostas por Wagensberg (2000) e Pavão e Leitão (2007): hands-on, mindson, hearts-on e explainers-on.

Quadro 2 - Respostas para a pergunta "Entre as coisas que você viu hoje no CST qual você mais gostou?"

\begin{tabular}{|c|c|}
\hline Entre as coisas que você viu hoje no CST qual você gostou mais? \\
\hline Atividade & Porcentagem \\
\hline Anatomia & $22,5 \%$ \\
\hline Artrópodes & $17,5 \%$ \\
\hline Inclusão & $15 \%$ \\
\hline Conhecendo suas Células & $12,5 \%$ \\
\hline Eletrocondutividade & $10 \%$ \\
\hline Cerebrino & $7,5 \%$ \\
\hline Outros & $7,5 \%$ \\
\hline Microscópio & $5 \%$ \\
\hline Algas & $2,5 \%$ \\
\hline Total & $\mathbf{1 0 0 \%}$ \\
\hline
\end{tabular}

Fonte: Elaborado pelos autores.

Por fim, a pesquisa mostrou que, quando perguntados "Na atividade dos artrópodes o que você mais gostou?", 67\% do público mencionou a preferência pela abordagem relacionada com os escorpiões (Figura 5). A caixa escura e a fluorescência dos escorpiões foram os itens que os visitantes mais gostaram dentro da atividade Artrópodes. Este equipamento despertou grande curiosidade no público, pondo-o de frente com sensações de estranhamento e dúvidas, consequentemente os mediadores foram questionados diversas vezes se ali dentro havia algum animal vivo. Nessas situações o papel do mediador era, ao mesmo tempo, incentivar a curiosidade e explicar os riscos de ter um animal vivo tão próximo e que, portanto, não era isso que ele veria. Vivenciar essa curiosidade, superar o medo do desconhecido e a posterior sensação de encantamento ou até de espanto, são exemplos de hearts-on e podem ser os motivos que levaram ao destaque da caixa escura nesta pergunta. 
Ensino, Saúde e Ambiente - V13 (1), pp. 122-143, Abr. 2020

\section{$\mathrm{Na}$ atividade dos artrópodes o que você mais gostou?}

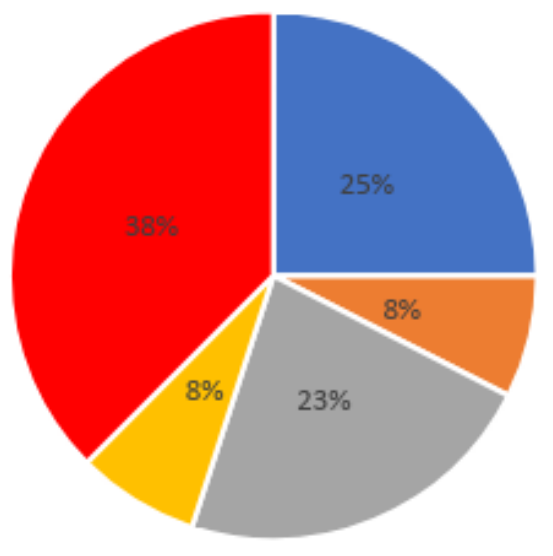

Insetos

Os escorpiões e mudas (casquinhas) fora da resina

- Os escorpiões na resina

não teve nada que eu gostei nessa atividade

- Os escorpiões na caixa da luz negra

Figura 5 - Respostas para a pergunta "Na atividade dos artrópodes o que você mais gostou?

Fonte: Elaborado pelos autores.

Filmagem de campo amplo

No que diz respeito à análise do vídeo foram registradas a participação de 194 pessoas na atividade Artrópodes durante todo o dia da exposição. Desse total, 44 retornaram à atividade totalizando 238 interações distintas. O tempo médio de participação foi de 3 minutos e 40 segundos sendo os mais rápidos 05 segundos e o mais longo 19 minutos. Este tempo médio está um pouco abaixo do encontrado em estudos anteriores para o CST que é de 5 minutos (ALVES, 2016).

Além do tempo, foram contabilizadas as formas de interação. Verificou-se que 22 pessoas realizaram registros fotográficos e 72 pegaram o escorpião ou a muda na mão (Figura 6). Isso representa quase $40 \%$ das interações e mostra que apesar da literatura descrever uma rejeição dos jovens e crianças aos artrópodes, ainda há muito outros que se interessam em interagir de forma segura com esses animais (BESERRA; BRITO, 2008; KIEM; RIBAS, 2015). 


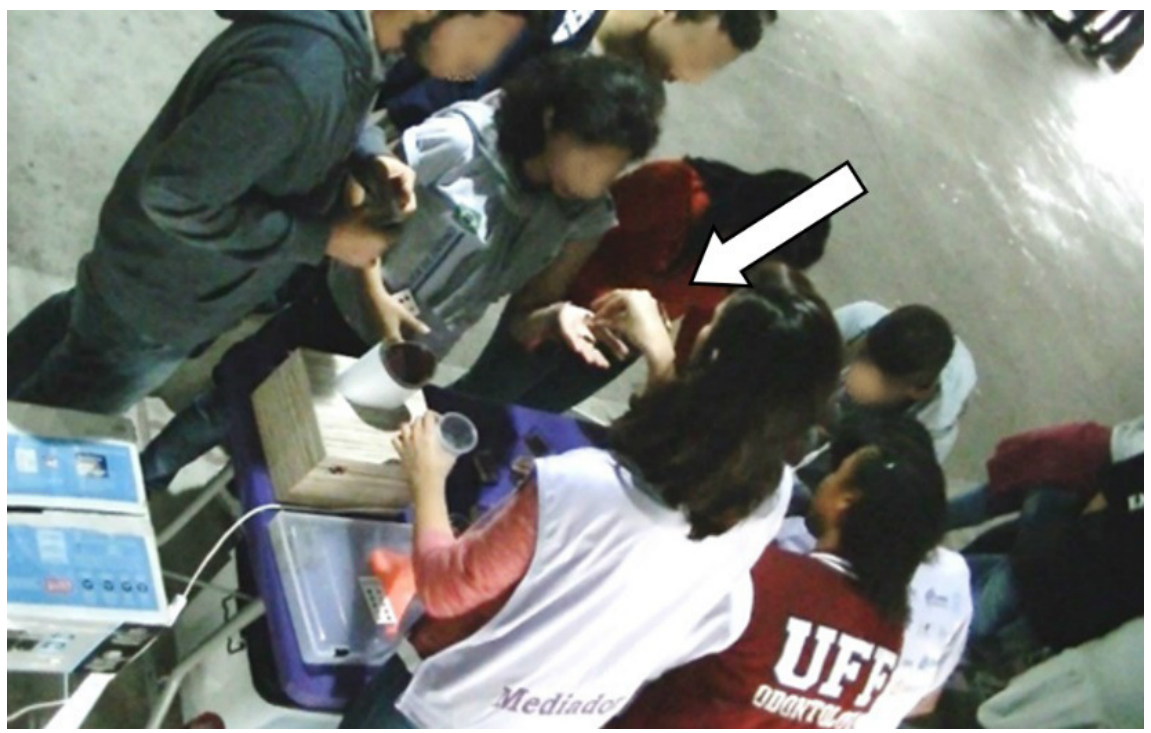

Figura 6 - Imagem da câmera usada para avaliar as interações. A seta indica a ação da mediadora colocando a carcaça de escorpião na mão do visitante.

Fonte: Elaborado pelos autores.

Também foram observados alunos que retornavam à atividade trazendo novas pessoas ou retornavam porque seus conhecidos ainda estavam junto à mesa. Alguns alunos foram observados saindo e voltando à atividade diversas vezes e interagindo tanto com as peças quanto com as mediadoras. Nessas situações, o mediador tem grande importância na construção do conhecimento, assim como o tempo dedicado àquelas informações da atividade (MARANDINO et al., 2008). Carvalho (2012) entende que, ao observar aqueles objetos o visitante pode ter encontrado a necessidade de responder seus questionamentos prévios. Assim, a cada interação, essa necessidade é renovada e cabe ao mediador incentivar esses questionamentos e garantir informações cientificamente corretas, principalmente no tocante à saúde.

Em contrapartida, diversos visitantes reagiram com medo ou nojo dos animais, principalmente dos escorpiões e mudas fora da resina. Essa reação pode ser consequência de um comportamento aprendido como forma de proteção, uma vez que são relacionados à problemas de saúde, o que influencia direta e negativamente na relação que é construída com os artrópodes em especial os aracnídeos (DA-SILVA, 2015; DE BARROS et al., 2013). Em decorrência disso, a importância ecológica, ambiental e biotecnológica desses artrópodes é, por muitas vezes, deixada de lado e negligenciada.

De igual modo, Miranda e Figueiredo (2009) observaram em sala de aula que as discussões sobre insetos despertavam mais interesse quando se travavam de morfologia ou fisiologia, mas nem tanto quando o assunto era interações inseto-humano. Foi observado que, em geral os alunos desconheciam os benefícios desse grupo e citavam apenas os prejuízos. 
Esses autores também constataram que o motivo do medo de insetos vinha do fato deles transmitirem doenças, viverem em locais sujos ou por serem estranhos.

Todavia, utilizar a incrustação em resina, como produto com fins educativos pode minimizar esses efeitos negativos. A partir de observações da percepção de estudantes sobre os insetos, Kiem e Ribas (2015) utilizaram uma coleção de animais incrustado em resinas com turmas do $7^{\circ}$ ano do Ensino Fundamental e seus resultados reportaram o interesse dos estudantes pela aula e pelo próprio material resinado. Através de afirmações como: "Eu gostei da ideia da resina porque podemos segurar o animal"; "Eu gostei muito das resinas porque me deixou mais à vontade, pois não gosto de muitos deles" e "Eu achei muito interessante as resinas, porque podíamos ver os bichos de perto e ver os detalhes" (p. 32), pode-se notar que a metodologia causou efeitos positivos naquelas turmas, assim como foi possível observar num ambiente de educação não formal, na atividade dos artrópodes no CST.

\section{CONSIDERAÇÕES FINAIS}

O Ciências Sob Tendas, em visita ao CIEP 172, alcançou seu objetivo de ampliar a oferta de atividades científicas lúdicas e interativas e de estimular a curiosidade e o pensamento crítico sobre ciências através da divulgação científica itinerante. Durante esta visita foram apresentados e avaliados os novos produtos para a atividade Artrópodes do CST.

A produção do material incrustado em resina, apesar de demandar tempo e atenção às várias etapas, pode ser reproduzida por diversos profissionais de educação e possui baixo custo de produção. Da mesma forma, a montagem da câmara escura é de fácil execução e possibilitou momentos de surpresas e descobertas para os visitantes. Contudo, deve-se observar o processo de obtenção das carcaças dos animais a fim de respeitar a legislação ambiental e atentar para os riscos à saúde humana.

Com base nos resultados obtidos foi possível perceber que, apesar dos animais da classe Arthropoda serem conhecidos pela maioria do público, sua presença na atividade Artrópodes do CST foi marcante no que diz respeito a interação do público, destacando-a positivamente entre as demais atividades da exposição. Além disso, a participação do público aliada a mediação proporcionou oportunidades para o diálogo em saúde, discutindo prevenção de acidentes, tratamento e outros temas, aproveitando momentos de interesse e curiosidade.

Diante do exposto, consideramos que a atividade dos Artrópodes no CST, é uma forma de divulgação científica que viabiliza a discussão de diversos temas, em especial temas de saúde. Seja através de doenças transmitidas por animais desse grupo, seja pela seção dedicada aos escorpiões que suscitou a discussão de acidentes com animais peçonhentos. Dessa forma, a atividade dos artrópodes cumpriu com seu papel social, científico e de educação em saúde, ao qual o Ciências Sob Tendas preconiza junto a sociedade. 


\section{AGRADECIEMNTOS}

O presente trabalho foi realizado com apoio da Coordenação de Aperfeiçoamento de Pessoal de Nível Superior - Brasil (CAPES) - Código de Financiamento 001; do Conselho Nacional de Desenvolvimento Científico e Tecnológico (CNPq); e da Fundação Carlos Chagas Filho de Amparo à Pesquisa do Estado do Rio de Janeiro (FAPERJ); pelo Programa de Bolsas de Extensão 2019 - Pró-Reitoria de Extensão/ Universidade Federal Fluminense. Agradecemos à equipe do aracnário do Instituto Vital Brazil, à Equipe do Setor de DST da UFF, à Lívia Mascarenhas e Maykon Motta Marins pelo apoio técnico no desenvolvimento deste trabalho.

\section{REFERÊNCIAS BIBLIOGRÁFICAS}

ABCMC. Centros e museus de ciência e tecnologia Centros e museus de ciência e tecnologia. p. 312. Disponível em: <www.abcmc.org.br >. Acesso em 6 nov. 2018

ALVES, Gustavo. H. V. S. Ciências Sob Tendas - Despertando para a Biotecnologia. 2016. 84 f. (Dissertação de Mestrado) Universidade Federal Fluminense, 2016 ANGROSINO, Michael. Etnografia e observação participante. (S.1.): Grupo A - Bookman. 2000

AQUINO, A. M.; AGUIAR-MENEZES, E. de L.; DE QUEIROZ, J. M. (2006)

Recomendações para Coleta de Artrópodes Terrestres por Armadilhas de Queda ("PitfallTraps"). Circular Técnica, EMBRAPA. Disponível em: $<$ https://ainfo.cnptia.embrapa.br/digital/bitstream/CNPAB-010/34091/1/cit018.pdf> Acesso em: 27 set. 2018.

ARTE EM RESINA. Disponível em: <https://www.youtube.com/channel/UCyeg 83SQdpVxS3ztnNZLLw> Acesso em: 5 fev. 2019

BELEI, R. A. et al. O uso de entrevista, observação e videogravação em pesquisa qualitativa. Cadernos de Educação 30 pp. 187-199. 2008

BERTANI, R., L. GODÉ, A. K. \& M.-L. C. Aracnídeos (Arachnida) da Reserva Biológica de Pedra Talhada. In: Nusbaumer, A. L. e Spichiger, R. Biodiversidade da Reserva Biológica Pedra Talhada. Eds. Studer, Alagoas, Brasil. pp. 175-191. 2015

BESERRA, Joallyson. G.; BRITO, Carlos. H. Modelagem didática tridimensional de artrópodes, como método para ensino de ciências e biologia. Revista Brasileira de Ensino de Ciência e Tecnologia, 5 (3). 2008

BIAZI, Angelo. H. Análise de agrupamentos para o reconhecimento de padrões de infestação de aracnídeos em zonas urbanas. 51f. 2015 (Dissertação de Mestrado)

Universidade Estadual Paulista, 2015

BRASIL (2001) Manual de diagnóstico e Tratamento de Acidentes por animais peçonhentos. 2. ed. Brasília: Ministério da Saúde.

. TabNet Win32 3.0: Acidentes por animais peçonhentos - Notificações registradas no Sistema de Informação de Agravos de Notificação - Brasil. http://tabnet.datasus.gov.br/cgi/tabcgi.exe?sinannet/cnv/animaisbr.def (Acesso em: 22 jul. 2018)

. Acidentes por animais peçonhentos - Escorpião. http://portalms.saude.gov.br/saudede-a-z/acidentes-por-animais-peconhentos-escorpiao (Acesso em: 29 jan. 2019)

. (2009) Ensino Fundamental de nove anos: Passo a passo do processo de impalntação. Brasilia: Ministério da Educação. Disponível em: < http://portal.mec.gov.br/index.ph p?option=com_docman \&view=download \&alias=700-passoapasso9anos-pdf \&Itemid $=30192>$ Acesso em: 1 jun. 2019 
BRITES NETO, José. Atividade escorpionicida de metabólitos secundários de Paecilomyces formosus em bioensaios in vivo com Tityus serrulatus Lutz \& Mello, 1922 (Scorpiones: Buthidae). 2018. 127 f. (Tese de Doutorado) Universidade de São Paulo, 2018. BUENO, Wilson. C. Comunicação científica e divulgação científica: aproximações e rupturas conceituais. Informação \& Informação v.15, n. esp., pp. 1-12. 2010

BUSATO, Maria. A. et al. Animais peçonhentos no ensino de Biologia : percepção de estudantes e professores de escolas públicas do oeste de Santa Catarina. Acta Scientiae v.17 n.3, pp. 781-791. 2015

CASTILHOS, Washington; ALMEIDA, Carla A expertise leiga vale para todos? O lugar das mulheres afetadas no debate sobre zika-microcefalia-aborto na imprensa brasileira. Journal of Science Communication, América Latina, v. 1, n. 1, p. 02.2018

CARVALHO, Tassiana. F. G. de C. (2012) A comunicação científica em museus de ciência e o papel do mediador. 175 f. 2012 (Dissertação de Mestrado) Universidade de São Paulo. 2012

CARVALHO, C; LOPES, T. O público infantil nos museus. Educação e Realidade, v. 41 (3) pp. 1-20, 2016

CASCAIS, Maria. G. A.; TERÁN, Augusto. F. Educação formal, informal e não formal na educação em ciências. Ciência em Tela, v.7 n.2, pp. 1-10. 2014.

CHEUNG, Rafaela.; MACHADO, Cláudio. Acidentes Por Animais Peçonhentos Na Região

Dos Lagos, Rio De Janeiro, Brasil. Journal Health NPEPS, v.2, n.1, pp. 73-87. 2017

CURY, M. X. (2005) Exposição: concepção, montagem e avaliação. São Paulo: Annablume DA-SILVA, Elidiomar. R. et al. Marvel and DC Characters inspired by Crustaceans. Acme

International Journal of Multidisciplinary Research, v.2, n. 12, pp. 1-12, 2014.

. Quem tem medo de aranhas? Análise da HQ Aracnofobia à luz da Zoologia. Revista

Urutágua, v. 32, 2015. Disponível em: <https://www.researchgate.net/pu

blication/290523515>. Acesso em 3 fev. de 2019.

DE BARROS, Priscila. D. S. et al. Zoofobia: o imaginário dos alunos da educação infantil do Cabo de Santo Agostinho - PE. XIII Jornada de ensino, pesquisa e extensão, 2013

Disponível em: http://www.eventosufrpe.com.br/2013/cd/resumos/R0359-3.pdf >Acesso em 25 de jun de 2018.

FERREIRA, Adriano. de M.; SOARES, Cynthia. A. A. A. Aracnídeos peçonhentos: análise das informações nos livros didáticos de ciências. Ciência \& Educação v. 14, n.2, pp. 307314, 2008

FONTOURA, Helena. A. Tematização como proposta de análise de dados na pesquisa qualitativa. In: Formação de Professores e Diversidade Cultural múltiplos olhares em Pesquisa. Org. A., F. H. Niterói. 2011

GADOTTI, Moacir. A questão da Educação Formal/Não-Formal. Institut International Des Droits De L'Enfant (Ide), p. 1-11, 2005.

GERMANO, Marcelo. G.; KULESZA, Wojciech A. Popularização da Ciência: uma revisão conceitual. Caderno Brasileiro de Ensino de Física v. 24, n.1, pp. 7-25, 2007

INSTITUTO BUTANTAN, Soros. Disponível em: <http://www.butantan.gov.br/produca o/soros/Paginas/default.aspx > Acesso em: 8 jan. 2018

INSTITUTO VITAL BRAZIL Disponível em: <http://www.vitalbrazil.rj.gov.br/ apresentacao.html> Acesso em: 7 ago. 2018

KIEM, Suelen Z.; RIBAS, Luiz G. D. S. (2015) Utilização de material zoológico emblocado em resina como recurso didático alternativo para o ensino de ciências e biologia. 46f. 2015 (Graduação em Ciências Biológicas) Universidade Federal do Paraná, 2015

LOURENÇO, W. R. What do we know about some of the most conspicuous scorpion species of the genus Tityus? A historical approach. Journal of Venomous Animals and Toxins including Tropical Diseases v. 21, n. 1, pp. 20, 10, 2015 Disponível em: http://www.jvat.org/content/21/1/20. Acesso em: $8 \mathrm{de} \mathrm{fev} \mathrm{de} 2018$. 
MARANDINO, Marta. et al. Educação em museus: a mediação em foco. São Paulo, 48 p., 2008

MARQUES, J. P. A “observação participante” na pesquisa de campo em educação. Educação em Foco, v. 19, n. 28, p. 263-284, 20 ago. 2016.

MIRANDA, Juliana A. de S.; FIGUEIREDO, Rodolfo A. Percepção e valores dos insetos no ensino fundamental de escola pública em Araraquara, SP. V EPEA - Encontro Pesquisa em Educação Ambiental. São Carlos, 2009

NASCIMENTO, Tatiana G; REZENDE, Mikael J. F. A produção sobre divulgação científica na área de educação em ciências: referenciais teóricos e principais temáticas. Investigações em ensino de ciências, v. 15, n. 1, p. 97-120, 2016

NENCIONI, Ana L. A. et al. Effects of Brazilian scorpion venoms on the central nervous system. Journal of Venomous Animals and Toxins including Tropical Diseases v.24, n. 1, pp. 3, 2018. Disponível em: https://jvat.biomedcentral.com/articles/10.1186/s40409-0180139-X Acesso em: 2 ago. 2018

PAVÃO, Antônio C.; LEITÃO, Angela Hands-on? Minds-on? Hearts-on? Social-on?

Explainers-on! In: Massarani, L.; Rodari, P.; Merzagora, M. Diálogo Ciência mediação em museus e centros ciência. Org. Rio de Janeiro: Museu da Vida/Casa de Oswaldo Cruz/ Fiocruz. pp. 40-46, 2007

RECKZIEGEL, Guilherme C. Análise do escorpionismo no Brasil no período de 2000 a 2010. 103f. 2014 (Dissertação de Mestrado) Universidade Federal de Pernambuco, 2014. ROCHA, Jessica N.; MARANDINO, Martha. Museus e centros de ciências itinerantes: possibilidades e desafios da divulgação científica. Edicc v. 3, n. 3 , pp. 49-58, 2017. Disponível em: http://revistas.iel.unicamp.br/index.php/edicc/article/view/5220/5968 Acesso em 13 de fev. de 2019

SOUZA, Cláudio M. V.; MACHADO, Cláudio. Animais Peçonhentos de Importância Médica no município do Rio de Janeiro. Journal Health NPEPS v.2, n. 1, pp. 16-39, 2017.

WAGENSBERG, Jorge. Principios fundamentales de la museología científica moderna. 2000. Disponível em: http://www.bcn.cat/publicacions/bmm/quadern_central/bmm55/5.

Wagensberg.pdf Acesso em: 13 out. 2018

\section{SOBRE OS AUTORES}

THAIS VARANDAS DE AZEREDO - Graduada em Ciências Biológicas na Universidade Federal do Estado do Rio de Janeiro, Especialista em Educação e Divulgação Científica pelo Instituto Federal do Rio de Janeiro, Mestranda em Ciências e Biotecnologia na Universidade Federal Fluminense.

LUCIANNE FRAGEL-MADEIRA - Professora Doutora Associada do Departamento de Neurobiologia da Universidade Federal Fluminense, pesquisadora chefe do Lab. Desenvolvimento e Regeneração Neural, membro das Pós-graduações stricto sensu em Neurociências, Ciências e Biotecnologia, e Ciência, Tecnologia e Inovação ambos da UFF e Coordenadora geral do Programa de extensão Ciências Sob Tendas.

CLAUdio MAURÍCIO VIEIRA DE SOUZA - Doutor em Ciências pela Fundação Oswaldo Cruz-FIOCRUZ (2018); Mestre em Patologia Experimental pela Universidade Federal Fluminense (1998). Especialista em Biologia de Serpentes Aranhas e EscorpiõesInstituto Butantan (1990), Coordenador de programas de extensão e divulgação científica do Instituto Vital Brazil

GRAZIELLE RODRIGUES PEREIRA - Doutora em Ciências Biológicas (Biofísica) pela Universidade Federal do Rio de Janeiro (2014), Mestre em Ensino de Biociências e Saúde 
(Instituto Oswaldo Cruz/FIOCRUZ), Especialista em Neuroeducação. Professora do Instituto Federal de Educação, Ciência e Tecnologia do Rio de Janeiro, atua como pesquisadora e docente permanente no Pós-Graduação stricto sensu em Ensino de Ciências (IFRJ) e docente do Mestrado Profissional em Educação, Gestão e Difusão Científica do Instituto de Bioquímica Médica Leopoldo de Meis da UFRJ.

ROBSON COUTINHO-SILVA - Professor Titular do Instituto de Biofísica Carlos Chagas Filho (IBCCF) da Universidade Federal do Rio de Janeiro (UFRJ). Chefe do Laboratório de Imunofisiologia IBCCF/UFRJ, e diretor científico do Museus Espaço Ciência Viva. Cientista do Nosso Estado CNE/FAPERJ, docente permanente nos Programas de Pós-Graduação em Ciências Biológicas - Biofísica, Ciências Biológicas - Fisiologia no IBCCF/UFRJ, e em Ensino em Biociências e Saúde IOC-FIOCRUZ

GUSTAVO HENRIQUE VARELA SATURNINO ALVES - Possui graduação em Ciências Biológicas Licenciatura e Bacharelado com ênfase em ecologia pela Universidade Veiga de Almeida, Mestrado em Ciências e Biotecnologia, na linha de Ensino e Divulgação de Ciências e Biotecnologia pela UFF e atualmente é doutorando em Ensino em Biociências e Saúde pelo IOC-FIOCRUZ. 